\title{
Forecasting the Dynamics of Morbidity/Disability of Young People in Ukraine
}

\author{
Drozdova Irina Vladimirovna*, Khramtsova Victoriia Victorovna, Honchar Yuliia Alexandrovna \\ Psycho-neurology, Psychotherapy \& Medical Psychology Group of the Department, State Institution "Ukrainian State Institute of Medical \\ and Social Problems of Disability Ministry of Public Health of Ukraine”, Dnipro City, Ukraine
}

\author{
Email address: \\ drozdova@ua.fm (D. I. Vladimirovna),xvv2004@gmail.com (K. V. Victorovna), gonchar.yulia@gmail.com (H. Y. Alexandrovna) \\ ${ }^{*}$ Corresponding author
}

\section{To cite this article:}

Drozdova Irina Vladimirovna, Khramtsova Victoriia Victorovna, Honchar Yuliia Alexandrovna. Forecasting the Dynamics of Morbidity/Disability of Young People in Ukraine. Psychology and Behavioral Sciences. Vol. 6, No. 5, 2017, pp. 105-109. doi: $10.11648 /$ j.pbs.20170605.15

Received: June 22, 2017; Accepted: July 7, 2017; Published: October 19, 2017

\begin{abstract}
In the current period of health care system reform in Ukraine the study of youth morbidity is particularly important due to the unfavorable demographic conditions in the country: increasing mortality and reducing fertility. In the light of this problem, approaches to the analysis and prediction of morbidity and disability of young people in Ukraine have been developed. The analysis of morbidity dynamics is done with our own design, using software that is the part of the Information technology of disability dynamics analysis. The results of analysis of the monitoring functioning of child morbidity in Ukraine, let the forecast be carried out in a short time series. The prevalence of all diseases In Ukraine for $2008-2016$ years among adolescents $15-18$ years increased by $38,87 \%$ (from 17037,06 to 23659,1 ), morbidity - by $32,32 \%$ (from 9444,78 to 12497,6 for 10 thousand population). During this period it took place the reduction of primary disability of people over 18 years among adult and working population. The highest among persons aged 18 years are the numbers of newly recognized disabilities in classes: mental and behavioral disorders (1431), congenital malformations, deformations and chromosomal disorders (1196), nervous system diseases (836 cases).
\end{abstract}

Keywords: Morbidity, Disability, Prediction, Epidemiology

\section{Introduction}

In the current period of health care system reform in Ukraine, a complex socio-economic situation of the population, there is a need in deeper study of children and adolescent morbidity, as of the future of the nation and the most important society resource $[3,4]$. The study of youth morbidity is particularly important due to the unfavorable demographic conditions in the country: increasing mortality and reducing fertility $[1,10,11]$. In the research works of the next authors $[1,2,10]$ had been shown an importance of child health quality under conditions of low birth rate that is largely dependent on parents' health, the nature of mother's pregnancy and birthing, quality and accessibility of health services for children and mothers.

European Regional Committee of the World Health Organization (WHO) has developed a European strategy
"Health and development of children and adolescents" to attract the attention to the health care of children. Ukraine was chosen by WHO European Regional Committee as a pilot region for the implementation of that Strategy [4, 13]. The strategy identifies major problems in health care system for children and adolescents as well as their solutions, based on the experience of WHO over the past decades [4, 13, 14]. One of its tasks is the development of information technologies for collecting, analyzing, storing and predicting the dynamics of fertility, morbidity, disability and mortality among child population and adapting them to the requirements and standards of the European Union. One of the solutions of this problem may be the development of new approaches to the analysis and forecasting of child, adolescent and individual over 18 morbidity in Ukraine. 


\section{Objective}

To develop approaches to the analysis and prediction of adolescent morbidity and primary disability of people over 18 years in Ukraine.

\section{Materials and Methods}

Prevalence and morbidity of adolescents (15-17 years) were studied in Ukraine from the statistics data of the Ministry of Health of Ukraine, according to F.12. "Statement of the diseases registered in patients living in the area of a certain health care service institution" in 2004-2008 and 2016, according to the International Classification of Diseases (ICD-10) [12].

Extended statistical information on the disability status of 18 years old people having the status of a "disabled child" in Ukraine contains "Report on the cause of disability, indications for medical, occupational and social rehabilitation" (p. 14). The report data analysis from 2013 has been used by the State Institution "Ukrainian State Institute of Medical and Social Problems of Disability Ministry of Public Health of Ukraine" for publishing the analytical and informative guide "Basic indicators of disability and activity of Ukrainian medical and social expert committees for... year" [9].

The analysis of morbidity dynamics is done with using software that is the part of the Information technology of disability dynamics analysis [5]. One of the elements of the developed Information technology of disability dynamics analysis is the computer technology for forecasting morbidity indicators, which are the time series forms:

$$
\left\{x_{t} ; t=\overline{1, n}\right\}
$$

where $x_{t}-$ is the value of primary disability due to pathology $x$, registered in $t$ - year; $n$ - the number of years during which the morbidity of adolescents was monitored.

The results of analysis of the monitoring functioning of child morbidity in Ukraine, let the forecast be carried out in a short time series. Taking that into account, the adaptive methods of short-term forecasting became the basis of the developed computer forecasting technology [6, 8]. Adaptive forecasting methods are based on the principle of exponential smoothing, which takes into account the degree of information obsolescence and due to adaptation to changes in the test series it allows to obtain reasonably accurate estimates of future values, but no more than three steps forward $[6,8]$.

In order to select the most appropriate adaptive prediction model, the preliminary research of morbidity time series was conducted basing on the criteria of randomness and series visual analysis $[6,8]$. The analysis of the survey results showed the presence of linear trends in a time series that justified the choice of models of linear growth of Holt, Brown and Box-Jenkins. At the core of these models is the hypothesis that the prognosis may be obtained by the formula:

$$
\hat{\mathrm{x}}_{\tau}(t)=\hat{a}_{1, t}+\hat{a}_{2, t} \tau
$$

where $\hat{x}_{\tau}(t)$ - the prognosis for $\tau$ steps forward, made in $t$-th year; $\hat{a}_{1, t}, \hat{a}_{2, t}-$ the estimates of adaptive model coefficients.

\section{Results and Discussion}

Data analysis of disease morbidity and prevalence among adolescents in Ukraine for 2004-2008, developed and used methods of medium and long-term forecasting which have been conducted earlier [7], showed the possibility of all diseases prevalence growth among adolescents (15-17 years); diseases of the blood and blood-forming organs and certain disorders involving the immune mechanism (anemia, including iron deficiency anemia); diabetes (insulindependent diabetes) and obesity; nervous system diseases (vascular dystonia); diseases of the eye and adnexa (including myopia); diseases of the respiratory system (including acute pharyngitis, tonsillitis, tracheitis, chronic disease of tonsils and adenoids, laryngitis and laryngotracheitis); diseases of the digestive system (including gastritis and duodenitis, functional disorders of the stomach, pancreas diseases); pregnancy, childbirth and the postpartum period; birth defects (malformations), deformations and chromosomal disorders; other diseases of the heart; diseases of the skin and subcutaneous tissue; menstrual disorders.

According to the calculations, it was predicted the increase in adolescents morbidity in Ukraine for all diseases; diseases of the blood and blood-forming organs and certain disorders involving the immune mechanism (including anemia, including iron deficiency anemia); nervous system diseases (including vascular dystonia); diseases of the eye and adnexa, ear and mastoid process; diseases of the respiratory system (including strep throat and tonsillitis, allergic rhinitis, chronic laryngitis, laryngotracheitis); diseases of the digestive system (including gastritis, functional disorders of the stomach, pancreas diseases); diseases of the skin and subcutaneous tissue; obesity; essential hypertension and other heart diseases; menstrual disorders, pregnancy, childbirth and the postpartum period.

These statistical reports [12] show that among adolescents between 2008 and 2016 the prevalence of all diseases increased by $38,87 \%$ (from 17037,06 to 23659,1 for 10 thousand of population), morbidity - to $32,32 \%$ (from 9444,78 to 12497,6 for 10 thousand of population) (table 1). 
Table 1. The prevalence of diseases among adolescents (15-17 years) in Ukraine for 2004-2008, long-term prognosis, for the 2016 and primary disability of 18 year old people with the status of "a disabled child".

\begin{tabular}{|c|c|c|c|c|}
\hline \multirow[b]{2}{*}{ Names of classes and specific diseases } & \multicolumn{3}{|c|}{$\begin{array}{l}\text { Diseases prevalence among adolescents of } \\
15-17 \text { years }\end{array}$} & \multirow{2}{*}{$\begin{array}{l}\text { Primary disability of } \\
18 \text { year old people } \\
\text { In } 2016 \text { to } 10 \\
\text { thousand population }\end{array}$} \\
\hline & $\begin{array}{l}\text { Average in 2004-2008 } \\
\text { for } 10 \text { thousand } \\
\text { population }\end{array}$ & $\begin{array}{l}\text { Long-term } \\
\text { prognosis }\end{array}$ & $\begin{array}{l}\text { In } 2016 \text { to } 10 \\
\text { thousand } \\
\text { population }\end{array}$ & \\
\hline All diseases & 17037,06 & 23659,10 & 21545,3 & * \\
\hline Certain infectious and parasitic diseases & 426,58 & 593,88 & 434,8 & 62 \\
\hline Neoplasms & 98,92 & 122,68 & 155,4 & 286 \\
\hline $\begin{array}{l}\text { Diseases of the blood and blood-forming organs and certain disorders } \\
\text { involving the immune mechanism }\end{array}$ & 142,48 & 289,77 & 220,0 & 143 \\
\hline Coagulation defects, purpura and other haemorrhagic conditions & 130,24 & 270,72 & 205,5 & 93 \\
\hline Endocrine, nutritional and metabolic diseases & 1293,22 & 1937,71 & 1503,7 & 595 \\
\hline Diffuse goiter of $2-3$ degrees & 90,00 & 131,34 & 78,8 & 33 \\
\hline Diabetes mellitus & 16,18 & 23,89 & 21,8 & * \\
\hline Including insulin-dependent diabetes mellitus & 14,94 & 23,86 & * & * \\
\hline Obesity & 139,02 & 285,69 & 293,9 & * \\
\hline Mental and behavioral disorders & 461,06 & 203,84 & 350,9 & 1431 \\
\hline Diseases of the nervous system & 1003,82 & 1307,88 & 1177,9 & 836 \\
\hline Including vegetative dystonia & 708,92 & 957,92 & 844,2 & * \\
\hline Diseases of the eye and adnexa & 1296,60 & 1864,21 & 1696,8 & 467 \\
\hline Including myopia & 538,88 & 805,30 & 792,2 & * \\
\hline Diseases of the ear and mastoid process & 366,28 & 368,24 & 427,3 & 412 \\
\hline Diseases of the circulatory system & 555,64 & 638,81 & 779,8 & 161 \\
\hline including chronic rheumatic heart diseases & 20,58 & $-2,12$ & 4,3 & * \\
\hline Diseases of the respiratory system & 5569,18 & 8249,18 & 8223,7 & 167 \\
\hline Including acute pharyngitis and acute tonsillitis & 335,46 & 580,95 & 57,1 & * \\
\hline Chronic disease of tonsils and adenoids & 452,18 & 698,58 & 501,7 & * \\
\hline Chronic bronchitis & 42,20 & $-17,03$ & 20,2 & * \\
\hline Asthma & 89,06 & 60,05 & 85,7 & * \\
\hline Diseases of the digestive system & 1701,84 & 2477,15 & 1919,3 & 79 \\
\hline In particular gastric and duodenal ulcer & 42,98 & 9,62 & 29,7 & * \\
\hline Gastritis and duodenitis & 564,16 & 737,17 & 517,2 & * \\
\hline Functional disorders of stomach & 41,92 & 93,59 & 185,7 & * \\
\hline The pancreas diseases & 28,68 & 52,09 & 45,8 & * \\
\hline Diseases of the skin and subcutaneous tissue & 813,36 & 1094,03 & 977,9 & 39 \\
\hline Diseases of the musculoskeletal system and connective tissue & 1568,02 & 1403,77 & 1628,9 & 492 \\
\hline In particular rheumatoid arthritis & 19,20 & 17,29 & 6,4 & * \\
\hline Diseases of the genitourinary system & 834,04 & 2141,82 & 1043,6 & 316 \\
\hline Including chronic glomerulonephritis & 120,78 & 232,83 & 7,1 & * \\
\hline Kidneys Infections & 94,10 & 167,95 & 142,4 & * \\
\hline $\begin{array}{l}\text { Congenital malformations, deformations and chromosomal } \\
\text { abnormalities }\end{array}$ & 180,08 & 245,99 & 257,2 & 1196 \\
\hline Injuries, poisoning and certain other consequences of external causes & 520,60 & 217,54 & 693,2 & 332 \\
\hline
\end{tabular}

Notes: * - cases of primary disability (among 18 year old people) and diseases prevalence (among 15-17 years adolescents) from the given nosological unit were absent in 2016 year (on 10 thousand of population).

The prevalence of all diseases of adolescents increased by the growth of certain infectious and parasitic diseases (by $1,92 \%)$; neoplasms $(57,1 \%)$; diseases of the blood and bloodforming organs and certain disorders involving the immune mechanism (to $54,41 \%$ ), including anemia (by $57,59 \%$ ); endocrine, nutritional and metabolic diseases (by 16,28\%), including diabetes (by 34,73\%); obesity (by 111,41\%); diseases of the nervous system $(17,34 \%)$, including vegetative-vascular dystonia (to $19,08 \%$ ); diseases of the eye and adnexa (to 30,87\%), including myopia (by $47,01 \%$ ); diseases of the ear and mastoid process (to $16,66 \%$ ); diseases of the circulatory system (to 40,34\%); diseases of the respiratory system (by 47,66\%), including tonsils and adenoids (at 10,95\%); diseases of the digestive system (by $12,78 \%$ ), functional disorders of the stomach (3, 4 times), diseases of the pancreas (to 59,69\%); diseases of the skin and subcutaneous tissue (by 20,32\%); diseases of the musculoskeletal system and connective tissue (by 3,88\%); diseases of the urinary system $(25,13 \%)$, including infections of the kidneys (by 51,33\%); congenital malformations, deformations and chromosomal disorders (at $42,83 \%$ ); injury, poisoning and certain other consequences of external causes (to $33,15 \%$ ). So, the highest growth rates of children diseases prevalence in Ukraine during 2008-2016 years were observed for the functional stomach disorders and obesity.

Only some nosological forms and classes of diseases for this period showed the decrease of morbidity: diffuse goiter 2-3 degrees - by $12,44 \%$, mental and behavioral disorders - by $23,89 \%$, chronic rheumatic heart disease - by $79,11 \%$, acute pharyngitis and acute tonsillitis - by $82,98 \%$, chronic bronchitis 
- by $52,13 \%$, asthma - by $3,77 \%$, gastric and duodenal ulcer at $30,89 \%$, gastritis and duodenitis - in $8,32 \%$, rheumatoid arthritis - at $66,66 \%$ and chronic glomerulonephritis - 94,12\%. So the highest rates of decline of children diseases prevalence in Ukraine during 2008-2016 years were observed for chronic glomerulonephritis, acute pharyngitis, acute tonsillitis and chronic rheumatic heart disease.

By the classes of diseases, the highest ranks on the prevalence among adolescents in 2016 place respiratory diseases $(8223,7)$, digestive $(1919,3)$ diseases of the eye and adnexa $(1696,8)$, of the musculoskeletal system and connective tissue $(1628,9)$, endocrine, nutritional and metabolic diseases $(1503,7)$, lower - neoplasms $(155,4)$, diseases of the blood-forming organs and certain disorders involving the immune mechanism $(220,0)$, congenital malformations, deformations and chromosomal abnormalities $(257,2)$ and mental and behavioral disorders $(350,9$ for 10 thousand population).

Dynamics of adolescent morbidity over these years, led to the reduction of primary disability for people over 18 years among adults and working population in $2013-3,1$ and 4,4, in $2014-2,9$ and 3,3 in $2015-2,7$ and 3,8 and in 2016-2,6 and 3,6 per 10 thousand population. However, the highest among persons aged 18 in 2016 remain the number of newly recognized disabled in classes: mental and behavioral disorders (1431), congenital malformations, deformations and chromosomal abnormalities (1196), diseases of the nervous system (836); the lowest - diseases of the skin and subcutaneous tissue (39), certain infectious and parasitic diseases (62) and diseases of the digestive system (79 cases).

The proposed approach to the analysis of the dynamics of youth morbidity / disability in Ukraine makes it possible to not only generalize data on morbidity / disability over a long period of time, set the leading trends during this period, assess the risk of increasing morbidity / disability as the result of various pathologies, but model the data on morbidity / disability for a certain period of time. All this is necessary for further improvement of organizational and methodological work of doctors and the development of targeted measures for the youth morbidity / disability prevention and reduction in Ukraine.

The prospects for further research of public health issues are to develop the youth morbidity / disability monitoring model in Ukraine with a list of indicators, monitored sources and its frequency, levels of surveillance, software for informational support of health care system functioning. For the study of multivariate dependent trends of morbidity / disability of population in Ukraine, it is necessary to use the methods of mathematical statistics, taking into account the ambiguity of the socio-economic, demographic, industrial, political and other features of the regions development.

\section{Conclusions}

The prevalence of all diseases in Ukraine for 2008 - 2016 years among adolescents $15-18$ years increased by $38,87 \%$ (from 17037,06 to 23659,1 ), morbidity - by $32,32 \%$ (from
9444,78 to 12497,6 for 10 thousand population). The prevalence of all diseases among adolescents increased due to the growth of neoplasms $-57,1 \%$, diseases of blood and blood-forming organs and certain disorders involving the immune mechanism - by $54,41 \%$, anemia - by $57,59 \%$, obesity - by $111,41 \%$, functional disorders of the stomach by 3,4 times, diseases of the pancreas - by $59,69 \%$, infections of the kidneys - by $51,33 \%$, congenital malformations, deformations and chromosomal disorders by $42,83 \%$.

During this period it took place the reduction of primary disability of people over 18 years among adult and working population from 3,1 and 4,4 in 2013 to 2,6 and 3,6 per 10 thousand population in 2016. However, the highest among persons aged 18 years are the numbers of newly recognized disabilities in classes: mental and behavioral disorders (1431), congenital malformations, deformations and chromosomal disorders (1196), nervous system diseases (836 cases).

The development of information technologies of health dynamics analysis for young people enables not only generalizing data on morbidity / disability over a long period of time, establishing their leading trends during this period, assessing the risk of increasing morbidity / disability as a result of various pathologies, but also modeling the data of morbidity / disability for a certain period of time. All this is necessary for further improvement of the organizational and methodological work of doctors and development of targeted measures for the prevention and reduction of youth morbidity disability in Ukraine.

\section{References}

[1] E. N. Beletskaya., T. D. Zemlyakova, T. A. Golovkova (2010). Donoral indicators of children's health in industrial areas. Scientific bulletin of National O. O. Bogomoletz Medical University, 27: 162-163.

[2] O. O. Dudina, A. V. Tereshenko (2014). Situational analysis of children's population health state. Bulletin of social hygiene and health protection organization of Ukraine (scientific and practical journal), 2 (60): 49-57.

[3] European strategy for child and adolescent health and development. Copenhagen, 2005, 23 p.

[4] Healthy children - the best investment in the future (2012). Website: https://100spravok.org/consulting/zdorovye-detiluchshaja-investicija-v-buduxhee.html

[5] Ipatov A. V., Drozdova I. V. "Information technology analysis of the dynamics of disability”. Dnepropetrovsk, 2012, 269 p.

[6] Kendall M., Stewart A. "Multivariate statistical analysis and time series". Moscow, 1976, 736 p.

[7] Schudro, S. A. (2011). Criterial value of social-hygienic factors and conditions of study in health formation of adolescents studying in comprehensive schools. Dissertation for the degree of doctor of medical sciences on specialty 14.02.01 - hygiene and occupational diseases (medical sciences). - Hygiene and medical ecology Institute of the NAMS of Ukraine, Kiev. 
[8] Lukashin Yu. P. Adaptive methods of short-term forecasting of time series: a tutorial. Moscow, 2003, 416 p.

[9] The main indicators of disability and the activities of medical and social expert commissions of Ukraine for 2016 (Analytical and information guide). Dnipro, 2017, 168 p.

[10] N. Ya. Panchishin, V. L. Smirnova, O. Ya. Galicka-Kharkhalis (2011). Morbidity of child's population of Ukraine and factors, which influencing on children health. Topical issues of pediatrics, obstetrics and gynecology, 2: 13-132.

[11] Human development in Ukraine: the transformation of living standards and regional dispositions (collective monograph), Kiev, 2012, 436 p.
[12] Statistics of the incidence of children in Ukraine. Website: http://medstat.gov.ua/ukr/statreports.html

[13] Strong M. A. The effects of adult mortality on infant and child mortality. Unpublished paper presented at the Committee on Population Workshop on the Consequences of Pregnancy. Maternal Morbidity and Mortality for Women, their Families and Society. Washington. Website: http: www.nap.edu/openbook.php record_id.

[14] United Nations Secretary-General Ban Ki-moon. Global Strategy for Women's and children's health (2011). - New York: Unated Nations, 2010. Website: http://www.un.org/sg/hf/Global_StrategyEN.pdf 